\title{
DESIGN CENTRADO NO USUÁRIO: CRIANDO RECURSOS DIDÁTICOS PARA IDOSOS
}

Márcia B. de Sales¹- Universidade Federal de Santa Catarina - marcia.barros@ufsc.br

Selma Dos Santos Rosa - UFSC - selmadossantosrosa@gmail.com

Sérgio A. A. de Freitas - Universidade de Brasília - UnB - sergiofreitas@unb.br

André Barros de Sales - Universidade de Brasília - UnB - andrebdes@unb.br

Resumo: Este artigo objetiva apresentar um relato de experiência da criação de recursos didáticos de informática básica para pessoas idosas. Nessa pesquisa, utilizou-se o design centrado no usuário objetivando torná-los mais acessíveis, precisos, concisos e inteligíveis para esses usuários. Este estudo envolveu a participação de 116 idosos, a maioria mulheres, com média de idade de 65 anos, apresentando escolaridade e classe social heterogêneas, todos concluintes do projeto de extensão "Oficinas de Informática para a Terceira Idade", entre 2008 a 2010, da Universidade Federal de Santa Catarina. Foram desenvolvidos dois recursos didáticos: um material didático impresso e duas videoaulas. Estes recursos didáticos foram avaliados pelo público-alvo por meio de questionários e com base em uma série de experimentos construídos em conjunto com estes usuários.

Palavras-chave: Idosos. Inclusão Digital. Design centrado no usuário. Acessibilidade.

\section{USER-CENTERED DESIGN: CREATING DIDACTIC RESOURCES FOR SENIORS}

\begin{abstract}
This article aims to present an experience report on the creation of basic computer teaching resources for seniors. In this research, we used user-centered design seeking to make them more accessible, accurate, concise and intelligible to those users. This study involved 116 seniors, mostly women, with a mean age of 65 years, with heterogeneous education and social classes, all graduates of the extension project "Computer Workshops for Seniors", between 2008-2010, of the Federal University of Santa Catarina. We developed two educational resources: a printed teaching material and two video classes. These educational resources were evaluated by the target audience through questionnaires and based on a series of experiments built with those users.
\end{abstract}

Keywords: Seniors. Digital Inclusion. User-centered design. Accessibility.

\section{Introdução}

Entre os problemas sociais vivenciados pelos brasileiros está a dificuldade de acesso às tecnologias da informação e comunicação, como computadores e, por extensão, internet, por exemplo. Presente em todas as faixas etárias, essa dificuldade tende a se agravar ainda mais com a perspectiva de crescimento da população idosa ${ }^{2}$. Os relatórios da Pesquisa Nacional por Amostra de Domicílio, realizada em 2005, revelaram que apenas 3,3\% das pessoas com mais de 60 anos acessaram a Internet nos três meses antecedentes à coleta dos dados (IBGE, 2010).

A população brasileira está se transformando de jovem para adulta e com uma tendência ao envelhecimento rápido, considerando a expectativa do incremento intenso de pessoas idosas nos próximos 20 anos. Em 2030, estima-se que 40\% de brasileiros 
deverão estar na faixa etária de 30 a 60 anos. Esse aumento vem modificando significativamente o desenho da pirâmide populacional do país, provocando o que os estudiosos chamam de retangularização (IBGE, 2010).

Objeto de estudo de diversas publicações (Czaja; LEE, 2007; Czaja; Sharit, 1999, Raabe et al., 2005; Dickinson et al., 2005; Sales, 2002; Sales; Xavier et al., 2004, entre outras) nos ambientes acadêmicos nacionais e internacionais, a interação "idosocomputador” tem sido discutida nas áreas de Interface Humano-Computador (IHC), Informática na Educação, Acessibilidade e Gerontecnologia. Esses estudos mostraram que o idoso se interessa pelo computador e consegue domínio básico no seu manejo, o que pode oferecer alguns benefícios, como a melhora na interação social e no estímulo mental.

Nos últimos anos, o Núcleo de Estudos da Terceira Idade (NETI) da Universidade Federal de Santa Catarina (UFSC) registrou que aproximadamente 100 idosos por semestre estavam interessados em aprender informática e navegar na Internet. Notou-se, porém, que alguns idosos que iniciavam os cursos de informática particulares queixavam-se do ritmo e da heterogeneidade da turma, que variava do jovem ao idoso, como também dos recursos didáticos que, segundo os idosos, em sua maioria lhes eram inadequados.

Entre as razões apontadas, destacaram que o material didático utilizado continha textos longos com muitas informações e poucas ilustrações, letras pequenas, palavras no idioma inglês sem tradução e poucos recursos de orientação, como, por exemplo, ilustrações sobre determinada tarefa ou ação que estava sendo ensinada ou pedindo que fosse executada etc. O resultado, consequentemente, foi que alguns idosos não conseguiam acompanhar o grupo no qual estavam inseridos, situação constrangedora que acabava por levá-los a abandonar as aulas de informática, e outros que se sentiam inseguros em muitas tarefas e não recorriam ao material didático por achar de difícil compreensão.

Essa falta de cuidado na elaboração/desenvolvimento de recursos didáticos pode influenciar significativamente no interesse do aprendiz idoso, dando-lhes a impressão de que o tema é complexo e difícil, podendo abater-se e acabar deixando o curso. Como se constatou, uma das razões desse problema é a falta de recursos didáticos adequados aos usuários idosos.

Em março de 2003, iniciou-se o projeto de extensão intitulado "Oficinas de informática para terceira idade”, no Departamento de Informática e Estatística da UFSC, com o apoio do Núcleo de Estudos da Terceira Idade. Em virtude da demanda, o projeto é renovado anualmente.

Este estudo soma-se ao esforço de pesquisa que vem sendo desenvolvida na área de IHC e usuários idosos, no sentido de promover a acessibilidade ${ }^{3}$ e a usabilidade para conceber recursos didáticos e materiais didáticos que sejam acessíveis, inteligíveis, usáveis, de forma que o idoso tenha suas necessidades atendidas e respeitadas suas experiências, ritmo, história de vida, auxiliando na promoção de sua inclusão digital.

O texto está dividido em quatro seções principais. Na primeira seção, serão apresentados alguns trabalhos relacionados de DCU e idosos. Na segunda, descrevem-se os passos metodológicos utilizando o DCU para os ciclos de desenvolvimento do material didático acessível e inteligível ao usuário idoso. Na sequência, apresentam-se as sistematizações das avaliações do material didático realizado com 116 idosos que participaram das oficinas de informática nos anos de 2008 a 2010. Com base nos resultados das avaliações, foi utilizada a mesma metodologia para construir duas vídeoaulas como tutoriais do material didático. Na última seção, finalmente são tecidas algumas considerações sobre a importância do uso do DCU. 


\section{Trabalhos relacionados}

É comum a crença de que os idosos resistem à mudança e não querem interagir com produtos de alta tecnologia, como computadores. No entanto, (Czaja et al, 2007), após analisarem dados disponíveis, confrontam amplamente esse estereótipo e indicam que os idosos são receptivos ao uso de computadores. Os autores afirmam que, para o idoso, o uso do computador, o treinamento, o apoio técnico, a facilidade de acesso e os tipos de aplicação disponíveis são determinantes para a sua receptividade.

O estudo de caso apresentado por ( Dickinson et al., 2005) mostra que é possível projetar mídias digitais efetivas e utilizáveis para idosos sem experiência prévia com computadores. Os pesquisadores enfatizam a importância da simplicidade ao projetar tecnologia para usuários idosos iniciantes de computador. Adicionalmente, descrevem uma abordagem clássica ao design de interface com o usuário: começar com os princípios de design e observar o feedback das interações com protótipo das interfaces vindos dos usuários.

(Gregor, Newell e Zajicek, 2002) analisam como idosos podem ter características muito diferentes devido às alterações decorrentes da idade e sugerem que princípios do DCU a serem empregados no desenvolvimento da tecnologia apropriada para esse grupo de usuários. Metodologias de DCU, no entanto, foram desenvolvidas para grupos de usuários com características relativamente homogêneas. Destacam ainda que os idosos englobam um grupo incrivelmente diverso de usuários, e mesmo pequenos subgrupos desse grupo tendem a ter maior diversidade em funcionalidade do que se encontra em grupos mais jovens.

Tema da discussão fomentada por (Raabe et al., 2005), "Promovendo inclusão digital dos idosos através de práticas de design participatório”, os idosos geralmente sentem-se excluídos do processo de evolução tecnológica. Para esse público, foi identificado o potencial da utilização de comandos de voz como alternativa aos periféricos tradicionais (teclado e mouse). Foram explorados também um protótipo de correio eletrônico e o bate-papo ativado por meio de comando de voz.

A pesquisa realizada por (Sayago et al., 2007) "Meeting Educational Needs of the Elderly in ICT: Two Exploratory Case Studies" enfatiza que existem muitas iniciativas de investigação de educar e incentivar o uso das tecnologias de informação e comunicação (TICs) entre as pessoas idosas. Salientam os autores que, mesmo assim, muito pouco se sabe sobre as necessidades educativas das pessoas idosas em tecnologia e os métodos para atingi-los. Neste relato, são apresentados dois estudos de caso exploratório que apontam necessidades educacionais de pessoas idosas no domínio das TICs. Participaram da pesquisa 10 usuários idosos e foram desenvolvidas duas videoaulas: um de email e outro de blog para idosos. Estas foram concebidas de forma interativa e participativa em conjunto com os idosos utilizando o DCU.

No estudo relatado no artigo "Introducing human-centered research to game design: designing game concepts for and with senior citizens”, (Abeele e Van Rompaey, 2006) apresentam uma metodologia centrada no humano para inovar jogos, baseada em princípios etnográficos e design participativo. Essa metodologia foi aplicada num projeto para desenvolver conceitos de jogos para idosos em seu 'habitat natural', pesquisando quais experiências positivas ocorriam em sua vida diária.

A pesquisa aqui relatada comunga das questões levantadas nas investigações de (Sayago et al., 2007), (Sales e Cybis, 2002), (Raabe et al., 2005; Abeele e Van Rompaey, 2006) acerca da importância de promover atividades participativas com idosos para construir e avaliar interfaces, informatizadas ou não, mais acessíveis e usáveis e, acima de tudo, que respeitem suas limitações, experiências de vida e desejos. 
A utilização da técnica de IHC do DCU foi abordada em (Sales e Fialho,2007c) e se teceu sobre as abordagens gerontológicas, educacionais, ergonômicas e iniciativas de inclusão digital focadas e mais adequadas para os adultos idosos.

\section{Material e Métodos}

Esta pesquisa está baseada principalmente nas orientações procedimentais da pesquisaação, método que reúne diversas técnicas de pesquisa social, com as quais se estabelece uma estrutura coletiva, participativa e ativa no nível da captação da informação, requerendo, portanto, a participação das pessoas envolvidas no problema investigado. Todo processo foi observado pela equipe técnica do projeto, uma ergonomista e um bolsista.

Primeiramente, formou-se, por meio de oficinas, um grupo de idosos interessados em atuar como multiplicadores voluntários dos conhecimentos obtidos nas oficinas de informática para outros aprendizes-idosos. Para apoiar esse multiplicador, foi necessário desenvolver materiais didáticos acessíveis, usáveis e inteligíveis. Recorreu-se, portanto, às técnicas de interface humano-computador e adotou-se o DCU.

Neste estudo, assumiu-se uma abordagem ergonômica para as atividades de observação e avaliação da interação dos idosos com o computador e suas ferramentas de comunicação e informação. Um dos princípios básicos da abordagem ergonômica é conhecer para modificar uma realidade de trabalho, informatizada ou não. Isso implica análise das situações reais como meio de identificar as necessidades dos usuários (CYBIS, 2002). A usabilidade é o conceito chave em como ajudar os usuários finais nas suas interações com o produto. Técnicas de usabilidade podem ajudar o projetista a conceber interfaces mais eficazes e eficientes, como, por exemplo, o DCU.

As avaliações foram coletadas por meio de questionários com questões de múltipla escolha entre participantes do projeto Infocentro que frequentaram as oficinas durante os anos de 2008 a 2010. Os alunos foram divididos em turmas de, no máximo, 10 alunos. Cada turma teve cerca de 30 oficinas, com dois encontros semanais de duas horas.

Para registrar os problemas de acessibilidade relatados pelos idosos nas oficinas, utilizaram-se câmera filmadora, máquina fotográfica, anotações manuais e formulário com questões subjetivas e objetivas ${ }^{4}$.

Para adequar os recursos didáticos com conteúdo de informática para os adultos idosos, foi essencial contemplar e privilegiar as premissas já desenvolvidas para o público adulto, a exemplo da andragogia 5 , tão defendida por autores pátrios como Paulo Freire, que prega uma educação que respeite a realidade do aprendiz, seus interesses, sua autonomia, diálogo (interação) e o uso de temas extraídos de uma problematização da prática de vida dos educandos.

Tomando como base a ISO 13407 e considerando as necessidades dos usuários idosos, devido aos declínios decorrentes da idade, foi criado um processo de DCU para desenvolver os recursos didáticos. Para a observação do processo de avaliação, utilizou-se a técnica empírica de oficinas de interação, que é apropriada para se trabalhar com o DCU, porque exige a participação direta dos envolvidos em interação real.

A adoção da pesquisa-ação neste estudo se deu pela flexibilidade dessas adequações sucessivas aos acontecimentos, favorecendo o emprego do DCU e legitimando o processo de observação durante a realização das oficinas de concepção de recursos didáticos para usuários idosos. 


\subsection{O desenvolvimento de material didático acessível para idosos}

Após a identificação da falta de material didático com conteúdos de informática que levassem em conta os declínios decorrentes da idade, as abordagens pedagógicas condizentes para adultos idosos e as questões de usabilidade, acessibilidade e inteligibilidade $^{6}$, notou-se a necessidade de conceber um material didático focando os itens mencionados para facilitar a aprendizagem do usuário idoso.

Para pôr em prática a utilização da técnica do DCU para idosos a fim de se elaborar o material didático, no início de 2006 foram convidados 10 idosos frequentadores das oficinas de informática ofertadas pelo Infocentro (LSC/UFSC), sendo três homens e sete mulheres, com grau de escolaridade heterogêneo (ensino fundamental completo a superior completo) e idades entre 56 e 68 anos, que colaboraram voluntariamente nas oficinas para avaliar os conteúdos já existentes no material e sugerir inclusão e/ou exclusão de conteúdos para o material didático (SALES et. al., 2007b). Durante as oficinas, os idosos foram consultados sobre o que eles gostariam de mudar, acrescentar ou retirar do material didático existente, e já utilizado por eles durante as oficinas de informática. Todas as sugestões e observações feitas pelos idosos foram anotadas para análise de viabilidade de adoção (SALES et. al., 2007b).

O primeiro protótipo do material didático contava com 8 atividades subdivididas em oficinas. O tópico de cada oficina constitui um passo a passo de determinado conteúdo com várias atividades propostas, tais como: Atividade 1 - Introdução; Atividade 2 - Motricidade; Atividade 3 - Editando e Formatando textos; Atividade 4 Pesquisa e Consulta na Internet; Atividade 5 - Projeto I; Atividade 6 - Correio Eletrônico (e-mail); Atividade 7 - Bate-papo - (chat - MSN e Skype); Atividade 8 Projeto II.

Aliada ao conteúdo, atenção especial foi dispensada a textos, cores, tipo e tamanho de fonte, imagens, figuras e indicações (sinalizações por meio de setas) que facilitavam a compreensão, indicação e assimilação dos conteúdos das oficinas. Esse cuidado foi tomado com a finalidade de atender às particularidades apresentadas pelo idoso, como, por exemplo, dificuldades de concentração e armazenamento de novas informações. Com a mesma intenção de melhorar a legibilidade do material didático, a sua impressão precisa ser realizada em cores com vistas a facilitar a associação do conteúdo impresso com a atividade que aparece no monitor do computador. Outra cautela adotada refere-se à encadernação do material didático com espiral para facilitar seu manuseio pelo idoso junto ao computador. Este material didático foi base para o primeiro livro de "Informática para Terceira Idade" disponibilizado na Biblioteca Nacional sobre o tema (SALES, 2007d).

Com o intuito de verificar a inteligibilidade e acessibilidade desse material didático, foi realizada uma avaliação com outros 55 idosos que participaram das oficinas em 2008 com idade média de 63 anos (desvio padrão $=7,6$ ) e grau de escolaridade heterogêneo do ensino fundamental até superior). Todos os participantes das oficinas frequentaram o Infocentro para Terceira Idade durante quatro meses com cerca de 30 oficinas. Os encontros ocorreram duas vezes por semana, com duas horas para cada turma usar o material didático.

No segundo semestre de 2009 foram realizados mais ajustes no material didático com a finalidade de torná-lo mais acessível e inteligível aos idosos aprendizes. Participaram 30 idosos com média de idade 66 anos (desvio padrão $=6,2$ ). Outra avaliação foi feita em 2010, foram 31 participantes com média de idade de 65 anos 
(desvio padrão $=7,1$ ). Abaixo, na tabela 1, apresentam-se as informações sobre idade e escolaridade desses participantes, que demonstra a grande diversidade desses dados.

\begin{tabular}{|c|c|c|c|c|c|c|}
\hline & \multirow[b]{2}{*}{$\begin{array}{l}\text { Faixa } \\
\text { etária }\end{array}$} & \multirow[b]{2}{*}{$\begin{array}{l}\text { Nr. de } \\
\text { idosos }\end{array}$} & \multicolumn{4}{|c|}{$\begin{array}{l}\text { Nível de } \\
\text { Escolaridade } \\
\end{array}$} \\
\hline & & & Básico & Fundamental & Médio & Superior \\
\hline \multirow{4}{*}{2008} & A & 16 & $0 \%$ & $19 \%$ & $44 \%$ & $38 \%$ \\
\hline & B & 21 & $0 \%$ & $14 \%$ & $62 \%$ & $24 \%$ \\
\hline & $\mathrm{C}$ & 10 & $20 \%$ & $10 \%$ & $50 \%$ & $20 \%$ \\
\hline & $\mathrm{D}$ & 8 & $0 \%$ & $25 \%$ & $63 \%$ & $13 \%$ \\
\hline \multirow{4}{*}{2009} & $\mathrm{~A}$ & 1 & $0 \%$ & $0 \%$ & $100 \%$ & $0 \%$ \\
\hline & B & 15 & $13 \%$ & $13 \%$ & $53 \%$ & $20 \%$ \\
\hline & $\mathrm{C}$ & 8 & $0 \%$ & $25 \%$ & $63 \%$ & $13 \%$ \\
\hline & $\mathrm{D}$ & 6 & $0 \%$ & $17 \%$ & $50 \%$ & $33 \%$ \\
\hline \multirow{4}{*}{2010} & A & 5 & $0 \%$ & $20 \%$ & $40 \%$ & $40 \%$ \\
\hline & B & 12 & $0 \%$ & $17 \%$ & $42 \%$ & $42 \%$ \\
\hline & $\mathrm{C}$ & 8 & $13 \%$ & $0 \%$ & $50 \%$ & $38 \%$ \\
\hline & $\mathrm{D}$ & 6 & $0 \%$ & $33 \%$ & $33 \%$ & $33 \%$ \\
\hline
\end{tabular}

Legenda: faixa A até 59 anos; faixa B de 60 até 65; faixa C de 66 a 70 anos; e faixa D: acima de 70 anos.

Nota-se a prevalência da faixa etária "B", de 60 até 65 anos, nos três anos investigados, e do grau de escolaridade relativamente alto entre os idosos aprendizes, porquanto a maioria deles possui o ensino médio ou superior. Em 2010, tinham cinco alunos que tinham 59 anos, mas todos eles completaram 60 anos durante o curso. Os participantes de 2008 encontram-se no grupo de escolaridade mais baixa e os de 2010 no de mais alta. O ensino médio predominou em todas as faixas etárias nos três anos de oficinas. Em geral, no perfil dos 116 idosos que participaram das oficinas de informática predominou o ensino médio ou superior e idade variando de 60 a 70 anos.

A seguir serão detalhados os passos para o desenvolvimento de vídeos-aulas para os usuários idosos.

\subsection{Desenvolvimento das videoaula}

$\mathrm{Na}$ tentativa de buscar recursos didáticos digitais para facilitar o aprendizado de conteúdos de informática abordados no material didático retrocitado, pensou-se em elaborar vídeoaulas com tutoriais ${ }^{7}$.

Para isso, primeiramente foram consultados alguns idosos multiplicadores participantes do projeto e foi apresentada a opção de se fazer um tutorial utilizando o recurso digital da vídeoaula. Os participantes aceitaram a proposta, já que o vídeo, com sua riqueza de detalhes e dinamismo, poderia auxiliar o aprendiz idoso no esclarecimento de suas dúvidas sobre as atividades do material quando não estivesse nas oficinas.

Além disso, a produção das vídeoaulas era uma alternativa viável, sem custo e de fácil acesso à equipe do projeto. Para os idosos, poderiam ser disponibilizados os vídeos em mídia digital para leitura em aparelhos de CD ou DVD.

Para pôr em prática o DCU idoso para a elaboração de recursos didáticos, em 2010, foram convidados 15 idosos que atuam como multiplicadores no projeto, selecionados por serem considerados pela equipe usuários experientes, já atuando no ensino de informática há mais de um ano. Os informantes tinham o seguinte perfil: 
quatro homens e 11 mulheres com escolaridade heterogênea, 6,67\% com ensino fundamental, 33,33\% ensino superior, com média de idade de 65 anos.

Estes 15 participantes foram convidados para participarem de uma oficina com duração de três horas, na qual foi explicada aos convidados a proposta da vídeoaula e, assim, foram apresentadas duas vídeoaulas. Essas aulas foram escolhidas levando em conta o grau de escolaridade dos alunos e o interesse sobre os assuntos tratados.

A primeira vídeoaula discorria sobre informática básica; a segunda, devido ao maior número de mulheres e ao interesse delas por trabalhos artesanais, foi selecionado um passo a passo sobre trabalhos manuais (cada uma com duração média de 12 minutos aproximadamente). A idéia foi mostrar como a vídeoaula pode ser usada como um passo a passo para abordar qualquer assunto. Após as apresentações, os idosos aceitaram de modo unânime esse recurso digital como um recurso a mais para o aprendiz-idoso.

Em seguida, os idosos foram consultados sobre quais atividades seriam mais interessantes abordar em um projeto piloto de vídeoaulas. Os informantes destacaram três assuntos que os aprendizes idosos sempre têm mais dificuldade durante as oficinas: acessar o e-mail; anexar fotos/arquivos no e-mail; e usar os recursos do programa de bate-papo, tais como: adicionar contatos, observar quando uma pessoa chama, mudar o status, trocar a imagem de exibição, etc. Segundo os participantes, essas atividades do material didático são as que suscitam mais dúvidas e os aprendizes esquecem da sequência de passos para realizá-las com segurança e autonomia. A primeira oficina findou com uma leitura pela equipe do projeto sobre as observações coletadas.

Posteriormente, para a viabilização da criação das vídeoaula, foram realizadas duas etapas. A primeira foi o momento de pesquisa e escolha de um software e do planejamento do tutorial das vídeoaulas. Aqui também foram definidos os conteúdos que seriam abordados no primeiro momento.

O software escolhido foi o Camtasia $^{8}$, porque esse programa captura com dinamicidade todas as operações de vídeo realizadas na tela do computador e áudio (locução do professor) explicando passo a passo determinada tarefa, como, por exemplo, organizar pastas e arquivos.

A primeira vídeoaula objetivou apresentar como acessar o e-mail e anexar documentos, fotos, imagens etc. O roteiro dessa aula começa na área de trabalho do computador, mostrando ao telespectador do vídeo como ele pode acessar a internet, logo seguindo de como acessar o e-mail; depois, quais os passos para compor um e-mail e procurar no arquivo do computador o documento que se quer anexar.

Em alguns momentos da vídeoaula, a equipe resolveu simular alguns "erros" para mostrar aos aprendizes a importância de colocar corretamente os endereços da internet e o nome de usuários.

Na segunda etapa, os mesmos 15 idosos que participaram da primeira oficina foram convidados novamente para outra oficina a fim de interagirem com as vídeoaulas elaboradas. Todo processo foi observado pela equipe técnica do projeto, formada por uma ergonomista e um bolsista, que registrou as queixas e dúvidas anotando as interações dos participantes. Primeiramente, foi feita uma explicação de como funcionava a execução da vídeoaula.

Em seguida, foram mostrados os comandos de acionamento para assistir à videoaula e interagir com ela: ligar, desligar, avançar, retroceder, utilizar a barra de rolamento do filme. Após as explicações, foi observada a interação dos participantes com as vídeoaulas, os quais realizaram as seguintes ações: escutar toda a vídeoaula; quando havia dúvidas sobre algo narrado, retrocedia, utilizando o botão voltar/retroceder na tela; fazia a mesma ação quando obtinha alguma informação nova. 
Percebeu-se também autonomia e segurança por parte desses usuários, devido à fácil utilização do recurso.

Em seguida, foi entregue aos idosos um questionário para avaliar as vídeoaulas. As questões de múltipla escolha abordavam os itens navegação, cores, layout, conteúdos e tópicos abordados nas vídeoaulas. Foi observado pela equipe do projeto o entusiasmo dos idosos multiplicadores com as vídeoaulas e alguns já sugeriram utilizála também durante as oficinas presenciais do projeto.

\section{Resultados e Discussão}

Primeiramente, será exposta a avaliação do material didático, depois as avaliações das vídeoaulas. No gráfico 1, são apresentados os resultados das avaliações de cada atividade contemplada no material didático. Essas avaliações foram obtidas por meio de questões de múltipla escolha, coletadas durante as oficinas de informática com os idosos no segundo semestre de 2008, variando de muito bom, bom, ruim e muito ruim. Para retratar as respostas mais objetivamente, optou-se por torná-las binárias, englobando os conceitos muito bom + bom = nota A; e ruim + muito ruim = nota B.

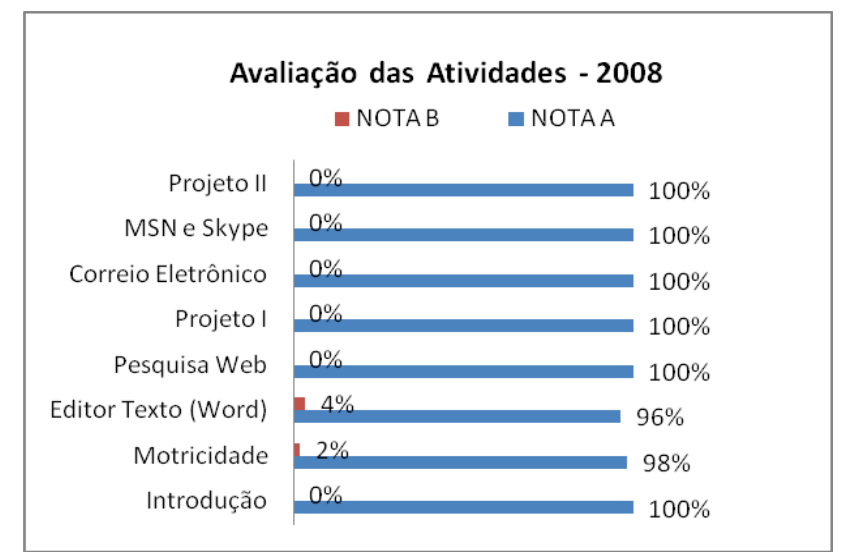

Gráfico 1 - Avaliação do material didático 2008

Especial atenção foi dispensada ao design de conteúdos do material didático, objetivando torná-los mais claros, precisos, concisos e inteligíveis aos usuários idosos. Contudo, buscou-se assegurar que o design respeitasse as características inerentes à idade e evitasse uma sobrecarga cognitiva relacionada à memorização dos comandos e ações, reduzindo a carga de trabalho do usuário.

As atividades Editor de Texto e Motricidade tiveram percentuais de 4\% e 2\%, respectivamente, de avaliação muito ruim dentre as oito atividades. Essas duas foram as que receberam os menores valores na avaliação. Na atividade "Motricidade", a grande barreira foi o mouse, pois se destinava a trabalhar a motricidade e a coordenação, geralmente prejudicadas nessa idade, fato já constatado em diversas pesquisas, entre elas a de Sales (2002).

Os gráficos 2 e 3, a seguir, mostram os resultados das avaliações das atividades dos anos de 2009 e 2010, respectivamente. 


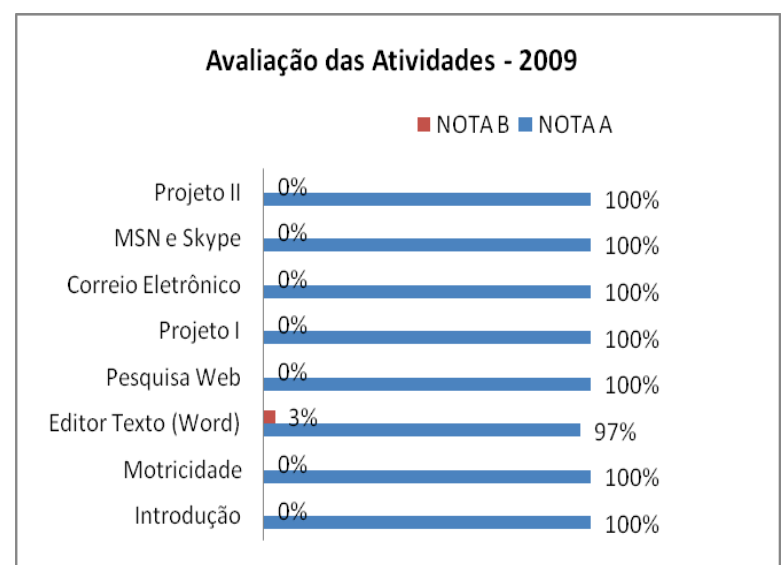

Gráfico 2 - Avaliação do material didático 2009.

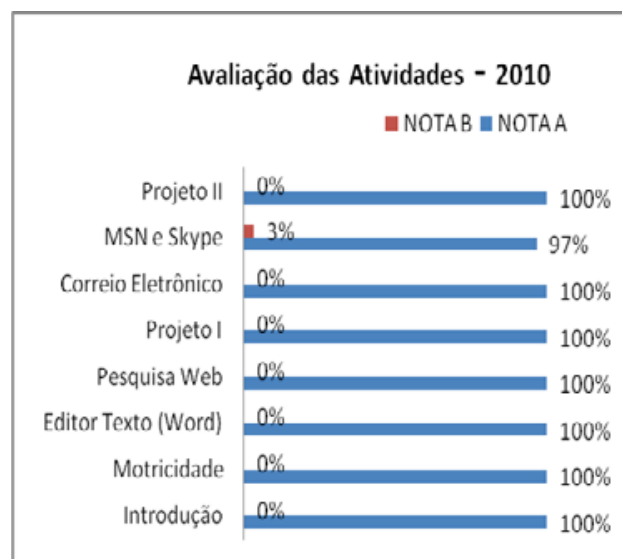

Gráfico 3 - Avaliação do material didático 2010.

Nota-se que a atividade Editor de Texto teve o percentual de 3\% de avaliação negativa em 2009. A dificuldade do idoso em utilizar o teclado que, na sua maioria, contém palavras em inglês, ou função das teclas representada por um sinal, e a falta de familiaridade com a máquina de escrever ou teclado foram alguns dos aspectos que influenciaram nesta avaliação, tanto na opinião dos idosos quanto na observação da equipe de pesquisa.

Já no ano de 2010, a atividade "Chat" ou bate-papo também teve 3\% de avaliação negativa, provavelmente por motivo de ordem técnica, porque nesse ano alguns computadores tiveram problemas, como vírus e defeito na placa de som do computador durante as atividades. Além disso, os idosos usavam essas máquinas tiveram de compartilhar com outros colegas do grupo o mesmo computador.

No grupo em estudo, os idosos aprendizes preferem atividades de navegação na internet para fazer consultas, pesquisas e também ferramentas de comunicação assíncrona (e-mail) e síncrona (bate-papo). Observou-se que houve melhora devido às contribuições (revisão da redação de alguns conteúdos, inserção de figuras e imagens indicativas e corte de textos desnecessários) dos participantes das oficinas idosos multiplicadores e das observações realizadas nas oficinas de interação pela equipe de pesquisa coletadas dos idosos aprendizes.

\subsection{Resultados das videoaulas}

A seguir serão apresentados relatos dos participantes coletados durante as oficinas sobre as videoaulas:

"Alunos saem da oficina pensando que sabe e quando chegam em casa esquecem os passos".

“Ótimo, que maravilha, claro o passo a passo".

“As imagens e o movimento com o que está acontecendo no computador a gente grava melhor”.

"No livro as imagens estão paradas, aqui é dinâmico, vai ajudar muito os idosos".

"É um reforço muito bom, porque o aluno aprende na oficina e em casa ele repete quantas vezes e hora que ele quiser, a gente se sente mais seguro".

"Depois da base dada aqui nas oficinas será muito bom a vídeoaula para o idoso".

"Os erros induzidos na vídeoaula foram muito bons porque mostra e reforça ao aluno onde ele tem que prestar mais atenção, fiquei mais confiante”. 
"Se você se perder no caminho de uma tarefa, você pode voltar pro começo e ver o passo a passo tudo de novo, sem medo de errar".

Diante dos resultados obtidos, foram feitas outras duas vídeoaulas sobre os conteúdos do e-mail e como acessar o programa de bate-papo. Os 15 idosos foram convidados para assistirem às novas vídeoaulas e fazerem uma avaliação utilizando um questionário com respostas de múltipla escolha no mesmo padrão de avaliação adotado na avaliação do material didático. Também foram aglutinados os resultados das questões: muito bom + bom $=$ resultado $\mathrm{A}$; e ruim + muito ruim $=\mathrm{B}$, conforme demonstrado no gráfico 4.

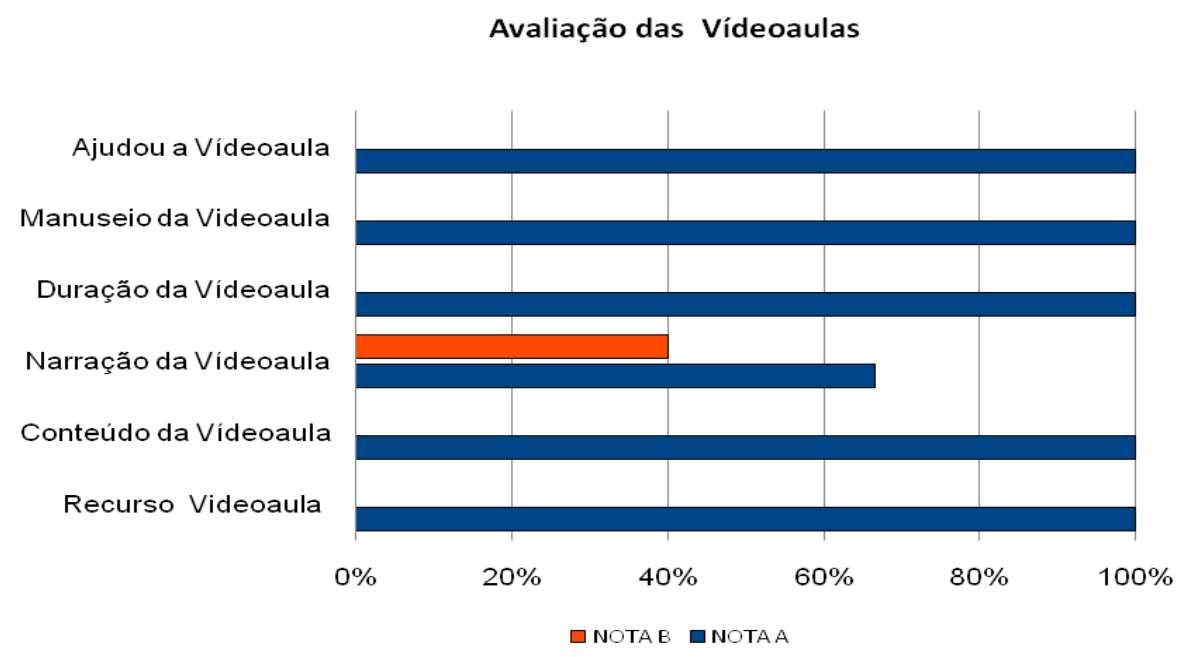

Gráfico 4 - Resultado da avaliação das duas vídeoaulas.

Como já constatado pelo relato dos idosos multiplicadores que participaram desse processo de criação das vídeoaulas, esse recurso digital foi plenamente aprovado. O item narração foi o único que teve $40 \%$ de índice negativo. Os idosos disseram que a voz do locutor estava muito baixa e, às vezes, fanhosa. Sugeriram utilizar uma voz mais alta e forte.

Os participantes foram unânimes em eleger o email e o bate-papo como suas ferramentas de comunicação preferidas, fato já observado nas avaliações realizadas para o desenvolvimento do material didático. Destacaram ainda algumas vantagens dessa mídia digital quando utilizadas pelos idosos aprendizes:

- dar oportunidade aos idosos que não têm computador em casa, visto que basta ter um aparelho de DVD-player;

- dar oportunidade, ao idoso-aprendiz de visualizar a dinâmica do que foi visto nas oficinas desde a primeira atividade do material-didático;

- por ser flexível e permitir que o idoso assista quando estiver disponível e quantas vezes quiser.

\section{Considerações finais}

O presente estudo contemplou o relato de experiência da aplicação do DCU para conceber três recursos didáticos acessíveis, usáveis e inteligíveis para usuários idosos, permitindo obter um primeiro feedback sobre as avaliações que indicaram o potencial da técnica do DCU como alternativa viável para desenvolver interfaces mais acessíveis, inteligíveis e usáveis, sejam elas informatizadas ou não.

Todas as informações coletadas foram registradas pela equipe do projeto. Notase que ainda resta muito a fazer. As sugestões estão sendo implementadas pela equipe de trabalho, assim como novas vídeoaulas. Além de fazer as vídeoaulas para apoiar o material didático, a idéia é também promover outras aulas para que os idosos 
multiplicadores possam capacitar-se, como: baixar e instalar um antivírus, gravar CD/DVD, organizar pastas e arquivos, acessar redes sociais, canais de vídeos entre outros.

Os resultados obtidos neste estudo evidenciam a importância de empregar o DCU para se obter interfaces de recursos didáticos, sejam eles digitais ou não, mais acessíveis, usáveis e inteligíveis para esses usuários.

Um dos pontos mais fortes da elaboração desses recursos didáticos foi 0 fornecimento de um feedback detalhado imediatamente após cada oficina para decidir como seria a interface de cada recurso, decisão que ajudou os alunos a entenderem melhor o assunto. Outro ponto forte foram as vídeoaulas que reforçaram os conhecimentos dos alunos, deixando-os mais seguros na interação com o computador e suas ferramentas, conforme disseram em seus relatos.

Os resultados das três avaliações utilizando o design centrado no idoso foram considerados satisfatórios. Essa afirmação também é ratificada pelas observações da equipe de pesquisa e no engajamento dos idosos participantes.

A presente pesquisa foi realizada em Florianópolis (SC), com um grupo de idosos com média de idade de 65 anos, todos alfabetizados, e, na sua maioria, com ensino médio e superior e do sexo feminino. É imperativo que, ao se planejar recursos didáticos para esse público, considerem-se as alterações cognitivas, emocionais e físicas decorrentes da idade, especificidades, necessidades, e escolaridade.

Em trabalhos futuros almeja-se divulgar os resultados da continuidade deste trabalho, e pretende-se desenvolver outras de videoaulas mais acessível, usável, inteligível e atrativas para as pessoas idosas. Pretende-se também, compartilhar e disponibilizar essas videoaulas a outros usuários em outros canais na internet.

\section{Notas}

${ }^{1}$ Supervisora pedagógica do Núcleo de Estudos da Terceira Idade (NETI/UFSC). Coordenadora do projeto de extensão “Oficinas de Informática para Terceira Idade” da UFSC desde 2003.

${ }^{2}$ A legislação brasileira considera idoso a pessoa com 60 anos ou mais.

${ }^{3}$ A perspectiva da acessibilidade explorada neste estudo é claramente social, relacionada aos usuários, e objetiva contribuir para que "nenhum obstáculo possa ser imposto ao indivíduo, diante de limitações sensoriais e funcionais" (GODINHO, 2002).

${ }^{4}$ Todos esses instrumentos tiveram a anuência dos participantes formalizada com o Termo Consentimento Livre e Esclarecido devidamente assinado, conforme Resolução 196/CNS.

${ }^{5}$ Definida por Knowles (1980) como “arte e a ciência de ajudar o adulto a aprender”.

${ }^{6}$ Inteligibilidade - Que pode ser facilmente compreendido: discurso inteligível.

${ }^{7}$ Tutorial vem da palavra tutor, visto que o seu objetivo é ensinar. Tutoriais são muito comuns na informática, usados para ensinar como programas funcionam e como podem ser operados por usuários iniciantes.

${ }^{8}$ O Camtasia é um programa que captura de tela e gravação de vídeos de tudo que está ocorrendo na tela do computador utilizados para tutoriais e treinamento online.

\section{Referências Bibliográficas}

ABEELE, V. V.; VAN ROMPAEY, V. Introducing human-centered research to game design. Game concepts for and by Senior Citizens. Proceedings of ACM SIG CHI, 2006. 
CYBIS, W. A. Engenharia ergonômica de usabilidade de interfaces humanocomputador. Pós-Graduação em Engenharia de Produção. Florianópolis: Universidade Federal de Santa Catarina, 2002. Apostila.

CZAJA, S.J.; GUERRIER, J.H.; NAIR, S.N.; LAUDAUER, T.K. Computercommunication as an aid to independence for older adults. Behaviour and information technology, v. 12, n. 4, , jul./ago., 1993. p. 197-207

; SHARIT, J. Performace of a complex computer - based trouble shootinf task

in the bank industry. Internacional journal of cognitive ergonomics and human factors, v. 3, p. 1-22, 1999.

.; LEE, C. C.. The impact of aging on access to technology. In: Universal access in the information society, v. 5, n. 4, 2007. p. 341-349.

DICKINSON, A.; NEWELL, AF; SMITH, M.J.; HILL, R.L. Introducing the Internet to the over-60s: Developing an email system for older novice computer users. Interacting with computers, v. 17, n. 6, dec. 2005.

GODINHO, F. Internet para necessidades especiais. 2002. Disponível: <http://www.acessibilidade.net/web>. Acesso em: 20 maio 2007.

GREGOR, P.; NEWELL, A. F.; ZAJICEK, M. Designing for dynamic diversity: interfaces for older people. ASSETS, 2002. p. 151-156.

IBGE. Cresce a presença da população com 50 anos ou mais no mercado de trabalho. Disponível

em:

$<$ http://www1.ibge.gov.br/home/presidencia/noticias/noticia_visualiza.php?id_noticia=6 48\&id_pagina=1>. Acesso em: 12 ago. 2009.

Projeção da população do Brasil. Disponível em: <http://www.ibge.gov.br/home/presidencia/noticias/30082004projecaopopulacao.shtm> . Acesso em: 12 jun. 2010.

RAABE, A. L. ; Oliveira RAABE, R.;XAVIER, A. J.; SALES, M. B. (2009). Promovendo inclusão digital dos idosos através da prática de design participatório. Revista Contrapontos, 5(3).. Promovendo inclusão digital dos idosos através de práticas design participatório. Contrapontos, Revista de Educação da Universidade do Vale do Itajaí, v. 5, n. 3., set./dez. 2005.

SALES, M. B. Desenvolvimento de um checklist para a avaliação de acessibilidade da Web para usuários idosos. 2002. Dissertação (Mestrado em Engenharia de Produção) Universidade Federal de Santa Catarina, Florianópolis, 2002.

.; FIALHO, F, A. P.; GUAREZI, R.. C. Infocentro para terceira idade: relato de experiência de aprendizagem por pares. Colabor@ - Revista Digital da CVA-RICESU, v.4, n.13, out. 2007a.

; FIALHO, F. A. P.; ALVAREZ, A. M. GUAREZI, R. C. Abordagem Pedagógica e Elaboração Material Didático Acessível para O Idoso. Athena.Revista Científica de Educação (Online). , v.8, 2007b. p.21 - 34.

Modelo multiplicador utilizando a aprendizagem por pares focado no idoso. 2007. Tese (Doutorado em Engenharia e Gestão do Conhecimento) - Universidade Federal de Santa Catarina, Florianópolis-SC, 2007c.

.;XAVIER, A. J. Metáfora e dinâmicas de grupo em oficina de internet para idosos. Conferência Ibero-Americana www/Internet, Algarve, Portugal, 8-9 nov. 2003. SAYAGO, S.; SANTOS, P.; GONZALEZ, M.; ARENAS, M.; LÓPEZ, L. Meeting educational needs of the elderly in ICT: two exploratory case studies. ACM Crossroads, vol 14, n. 2, dec. 2007.

W3C. World Wide Web Consortium. Web Accessibility Initiative: Ageing Education. W. Web Content Acessibility Guidelines 1.0. Disponível em: <http://www.w3.org/WAI/WAI-AGE/>. Acesso: 12 jun. 2011. 